\title{
Comparative Study of a Single-Incision Laparoscopic and a Conventional Laparoscopic Appendectomy for the Treatment of Acute Appendicitis in Children
}

\author{
Hayet Zitouni ${ }^{1}$, Hamdi Louati ${ }^{1}{ }^{*}$, Ahmed Turki ${ }^{2}$, Ahmed Guirat ${ }^{2}$, Mahdi Ben Dhaou ${ }^{1}$, Rafik Mzali ${ }^{2}$, \\ Riadh Mhiri ${ }^{1}$ \\ ${ }^{1}$ Department of Pediatric Surgery, Hedi Chaker Hospital, Medical University of Sfax, Sfax, Tunisia \\ ${ }^{2}$ Department of Surgery, Habib Bourguiba Hospital, Medical University of Sfax, Sfax, Tunisia
}

Email address:

drhamdilouati85@yahoo.com (H. Louati)

${ }^{*}$ Corresponding author

\section{To cite this article:}

Hayet Zitouni, Hamdi Louati, Ahmed Turki, Ahmed Guirat, Mahdi Ben Dhaou, Rafik Mzali, Riadh Mhiri. Comparative Study of a SingleIncision Laparoscopic and a Conventional Laparoscopic Appendectomy for the Treatment of Acute Appendicitis in Children. Advances in Surgical Sciences. Vol. 7, No. 3, 2019, pp. 71-74. doi: 10.11648/j.ajcem.20190703.12

Received: July 7, 2019; Accepted: July 26, 2019; Published: September 20, 2019

\begin{abstract}
Appendicitis is the most common indication for urgent surgery in children. Single-incision laparoscopic surgery (SILS) has further improved surgical outcomes. In this study we compared SILS and conventional in terms of peroperative difficulty and outcomes. A retrospective chart review was performed interesting all patients operated for acute appendicitis in the department of pediatric surgery Hedi Chaker hospital and department of surgery Habib Borguiba hospital between January 2006 and December 2016. Among the total of 181 patients, LA and SILS were performed respectively on 51 (28.2\%) and 137 patients (71.8\%). In $41.9 \%$ of patients of conventional LA it was a complicated appendicitis and in $29.8 \%$ of SILS group it was a complicated appendicitis $(\mathrm{p}=0.22)$. The mean operative time was $63.7 \mathrm{~min}$ for the conventional LA group and $71.79 \mathrm{~min}$ for the SILS group, it was not statistically significant $(\mathrm{p}=0.046)$. Conversion was made in $13.7 \%$ of patients in the conventional LA and in $5.8 \%$ in patients with SILS ( $\mathrm{p}=0.14$ ). The median length of hospital stay was for the conventional LA group 3.5 days and for SILS group 2.3 days $(\mathrm{p}=0.04)$. The current study found that SILS provided comparable surgical outcomes to conventional LA and did not result in increased postoperative complication rates.
\end{abstract}

Keywords: Appendectomy, Laparoscopy, Conventional, Children

\section{Introduction}

Appendicitis is the most common indication for urgent surgery in children [1]. The laparoscopic approach has gained wide acceptance among pediatric surgeons [2]. Although multiport laparoscopic mainly used for appendectomy recently single incision laparoscopic is more and more performed for pediatric appendectomy [3]. Minimally invasive singleport laparoscopic techniques, such as singleincision laparoscopic surgery (SILS) have further improved surgical outcomes, providing virtually scar-free surgery when performed by an experienced surgeon [4]. In this study we compared SILS and conventional in terms of peroperative difficulty and outcomes.

\section{Patients and Methods}

A retrospective chart review was performed interesting all patients operated for acute appendicitis in the department of pediatric surgery Hedi Chaker hospital and department of surgery Habib Borguiba hospital between January 2006 and December 2016. We excluded patients older than 16 years old, those operated by open approach or with history of previous laparotomy.

The study comprised retrospectively children who underwent SILS $(n=137)$ or a conventional LA $(n=51)$ for acute appendicitis between January 2006 and December 2016 in the department of pediatric surgery in Hedi Chaker hospital in Sfax and the department of general surgery in 
Habib Bourguiba hosptital in Sfax.

All data concerning age, gender, peroperative findings, a conversion, operative time, length of stay, outcomes and complications were collected and compared between the group of patients with multiport laparoscopic appendectomy and the group of patients with single incision laparoscopic appendectomy. All data was analyzed by SPSS version 20 and the statistical analysis was made by our team. All tests were carried out using $\mathrm{p}<0.05$ as the significance level.

Surgical method of SILS [5] (Figure 1):

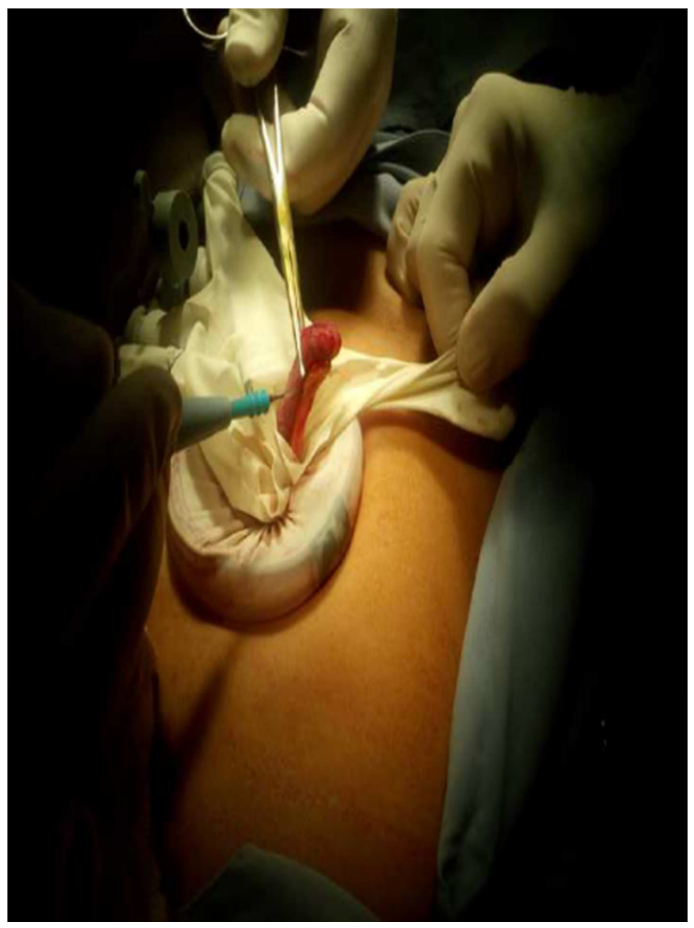

Figure 1. Peroperative view of SILS appendectomy.

The glove port needs a flexible ring, a rigid larger ring, one powder-free surgical glove, a wire-to-skin and laparoscopic trocars. At the beginning of the procedure, the fingertips of the glove are cut-off where the trocars are inserted and fixed. Then, the open end of the glove is passed through the flexible ring and turned around it in the middle of the glove. Afterwards, a $2 \mathrm{~cm}$ skin incision at the level of the umbilicus and peritoneum opening are generally sufficient to introduce the flexible ring covered by the glove into the abdominal cavity. The open end of the glove surrounds then closely the rigid ring. Pneumoperitoneum could be created by carbon dioxide insufflations through one of the trocars. Conventional laparoscopic instruments and a $0^{\circ}$ laparoscope are also introduced into the abdominal cavity through these trocars. At the end of the operation after appendectomy through the umbilicus the specimen is pulled out. We close then the muscle fascia by vicryl $2 / 0$ sutures and the umbilical skin using the rapid vicryl sutures.

\section{Results}

Among the total of 181 patients, LA and SILS were performed respectively on $51(28.2 \%)$ and 137 patients $(71.8 \%)$. The mean age was 10 years for conventional LA group and 9 years for SILS group $(\mathrm{p}=0.41)$. The sex ratio was 0.7 for conventional LA group and 0.9 for SILS group $(\mathrm{p}=0.65)$. In $41.9 \%$ of patients of conventional LA it was a complicated appendicitis and in $29.8 \%$ of SILS group it was a complicated appendicitis $(\mathrm{p}=0.22)$. The operative time was calculated from the time of skin incision until wound closure. The mean operative time was $63.7 \mathrm{~min}$ for the conventional LA group and $71.79 \mathrm{~min}$ for the SILS group, it was not statistically significant $(\mathrm{p}=0.046)$. Conversion was made in $13.7 \%$ of patients in the conventional LA and in $5.8 \%$ in patients with SILS, the difference was not statistically significant $(\mathrm{p}=0.14)$ (Table 1$)$.

Table 1. Comparative pre and peroperative characteristics between conventional LA and SILS.

\begin{tabular}{llll}
\hline & Conventional LA & SILS & P \\
\hline Age & 10 & 9 & 0.41 \\
Sexe: $\mathrm{F}$ & 27 & 82 & 0.65 \\
F & 24 & 55 & \\
BMI & & 48 & \\
Obese & No determined & 89 & \\
NO obese & $13.7 \%$ & $5.8 \%$ & 0.14 \\
Conversion open procedure & 63.7 min & 71.79 min & 0.46 \\
Operative time & & & \\
Appendix & $58.1 \%$ & $70.2 \%$ & 0.22 \\
Simple & $41.9 \%$ & $29.8 \%$ & \\
Complicated & & \\
\hline
\end{tabular}

The median length of hospital stay, that is, days spent from wound closure until discharge was for the conventional LA group 3.5 days and for SILS group 2.3 days and it was statistically significant $(\mathrm{p}=0.04)$. In the group of conventional LA 10 complications occurred (19.6\%) (4 wound infection, 2 intra-abdominal abscess, 3 postoperative ileus and one small bowel adhesion) compared to 13 complications for SILS (9.5\%) (2 wound infection, 1 intra-abdominal abscess, 7 postoperative ileus, 1 umbilical hernia and one small bowel adhesion), the difference was not statistically significant $(p=0.26)$. The mean of follow up was 24.6 months for conventional LA and 20.62 months for SILS (Table 2). 
Table 2. Comparative postoperative characteristics between conventional LA and SILS.

\begin{tabular}{llll}
\hline & Conventional LA & SILS \\
\hline Hospital stay & 3.5 days & 2.3 days \\
Complications & 10 & 13 \\
Wound infection & 4 & 2 \\
Intra abdominal abscess & 2 & 1 \\
postoperative ileus & 3 & 7 \\
Hernia & 0 & 1 \\
Small bowel adhesion & 1 & 2 \\
Follow up & 24.6 months & 20.62 months \\
\hline
\end{tabular}

\section{Discussion}

The SILS appendectomy in children was first described by Esposito in 1998 [6]. SILS is gaining popularity, and several authors have reported the feasibility of appendectomy using this technique [7]. Recently, numerous reports appeared in the literature describing the socalled SILS technique where a single umbilical trocar is used to introduce three or four instruments to perform a laparoscopic appendectomy [8].

Golebiewski et al stated that SILS is a safe and effective approach for treatment of early appendicitis [9]. The benefits of this technique include better cosmesis, shorter operative time and decreased costs compared with conventional LA [9]. In our series, $29.9 \%$ of cases in SILS group were advanced stages of appendicitis and it was not a problem for the realization of SILS. Petnehazy et al suggest that TULAA can be a simpler approach for appendectomy in obese children [10], and even if we did not stratify our population by weight in the present study, a single incision has proved to be a quick and effective approach for this kind of patients also in our hands.

Teoh et al reported that no statistically significant difference was detected in the operation time and admission days between the SILS and the LA groups [11]. Park et al also suggested that no statistical differences were present between the LA and the SILS groups when the operation time and the admission days were compared [12]. In our study we found that operative time was statically better with SILS group and this seems because our center has a particular interest in SILS, and we suggest that well-trained laparoscopic surgeons can perform single-port appendectomies without increasing their operation time.

The conversion rate for SILA in our study was low (5.8\%). Early reports suggested that SILA might be associated with a higher incidence of wound infection [13]. However, as laparoscopic techniques and equipment have improved, recent studies have reported that SILA has similar postoperative complication rates to conventional LA [14]. Kim et al reported that more intense pain was generated with the SILS technique than with the LA technique [15]. Mayer et al reported that the pain was less severe postoperatively in the SILS group compare with the LA group [16]. In our study there was no statistic difference in postoperative complications between SILS and conventional LA.
In SILS interferences and collisions between surgical instruments are worse than they are when a LA is performed using three incisions and securing a surgical view is problematic due to parallel placements of the camera and the instruments [15]. Some reports have stated that the use of flexible laparoscopic instruments instead of straight instruments may reduce the collisions between instruments [17]. In our department the frequently use of SILS improved our outcome and our operative time.

\section{Conclusion}

The current study found that SILS provided comparable surgical outcomes to conventional LA and did not result in increased postoperative complication rates. Furthermore with amelioration of the learning curve of SILS operative time should be ameliorating. The standardization of SILS for appendicitis surgery in children is possible because of its esthetic advantage with fewer scars and its low rate of postoperative complications. It must to get used as soon as possible by the young pediatric surgeons to ensure a good learning curve.

\section{Conflict of Interest}

The authors declare that they have no competing interests.

\section{Source of Support}

Nil.

\section{References}

[1] CODRICH, D., SCARPA, M. G., LEMBO, M. A., et al. Transumbilical laparoassisted appendectomy: a safe operation for the whole spectrum of appendicitis in children - a singlecentre experience. Minimally invasive surgery, 2013, vol. 20.

[2] K. Semm, "Endoscopic appendectomy," Endoscopy, vol. 15, no. 2, pp. 59-64, 1983.

[3] Towfigh S, Chen F, Mason R et al. Laparoscopic appendectomy significantly reduces length of stay for perforated appendicitis. Surg Endosc 2006, 20: 495-499.

[4] Froghi F, Sodergren MH, Darzi A, et al. Single-incision laparoscopic surgery (SILA) in general surgery. A review of current practice. Surg Laparosc Endosc Percutan Tech 2010; 20: 191-204. 
[5] MAHDI, Ben Dhaou, RAHMA, Chtourou, MOHAMED, Jallouli, et al. Single-port laparoscopic surgery in children: A new alternative in developing countries. African journal of paediatric surgery: AJPS, 2015, vol. 12, no 2, p. 122-125.

[6] Esposito C One-trocar appendectomy in pediatric surgery. Surg Endosc 1998, 12: 177-178.

[7] Oltmann SC, Garcia NM, Ventura B et al. Single-incision laparoscopic surgery: feasibility for pediatric appendectomies. J Pediatr Surg 2010, 45: 1208-1212.

[8] N. M. Chandler and P. D. Danielson, "Single-incision laparoscopic appendectomy vs multiport laparoscopic appendectomy in children: a retrospective comparison," Journal of Pediatric Surgery, vol. 45, no. 11, pp. 2186-2190, 2010 .

[9] Golebiewski A, Losin M, Murawski M, Wiejek A, Lubacka D, Czauderna P. One, two or three port appendectomy-a rational approach. Videosurg Miniinv 2013, 8 (3): 226-231.

[10] X. Li, J. Zhang, L. Sang et al., "Laparoscopic versus conventional appendectomy - a meta-analysis of randomized controlled trials," BMC Gastroenterology, vol. 10, article 129, 2010 .

[11] Teoh AY, Chiu PW, Wong TC, Wong SK, Lai PB, Ng EK. A case controlled comparison of single-site access versus conventional three-port laparoscopic appendectomy. Surg Endosc 2011; 25: 1415-9.
[12] Park J, Kwak H, Kim SG, Lee S. Single-port laparoscopic appendectomy: comparison with conventional laparoscopic appendectomy. J Laparoendosc Adv Surg Tech A 2012; 22: $142-5$.

[13] Teoh AY, Chiu PW, Wong TC, Wong SK, Lai PB, Ng EK. A case-controlled comparison of single-site access versus conventional three-port laparoscopic appendectomy. Surg Endosc 2011; 25: 1415-9.

[14] Ahmed I, Cook JA, Duncan A, Krukowski ZH, Malik M, MacLennan G, et al. Single port incision laparoscopic surgery compared with standard three-port laparoscopic sugery for appendicectomy: a randomized controlled trial. Surg Endosc 2015; 29: 77-85.

[15] Kim HO, Yoo CH, Lee SR, Son BH, Park YL, Shin JH, et al. Pain after laparoscopic appendectomy: a comparison of transumbilical single-port and conventional laparoscopic surgery. J Korean Surg Soc 2012; 82: 172-8.

[16] Mayer S, Werner A, Wachowiak R, Buehligen U, Boehm R, Geyer C, et al. Single-incision multiport laparoscopy does not cause more pain than conventional laparoscopy: a prospective evaluation in children undergoing appendectomy. J Laparoendosc Adv Surg Tech A 2011; 21: 753-6.

[17] Kang DB, Lee SH, Lee SY, Oh JT, Park DE, Lee C, et al. Application of single incision laparoscopic surgery for appendectomy in children. J Korean Surg Soc 2012; 82: 110-5. 